\title{
Gambaran length of stay pada pasien stroke rawat inap di RSUP Prof. Dr. R. D. Kandou Manado periode Juli 2015-Juni 2016
}

\author{
${ }^{1}$ Reunita C. Amiman \\ ${ }^{2}$ Melke J. Tumboimbela \\ ${ }^{2}$ Mieke A. H. N. Kembuan
}

\author{
${ }^{1}$ Kandidat Skripsi Fakultas Kedokteran Universitas Sam Ratulangi Manado \\ ${ }^{2}$ Bagian/SMF Neurologi Fakultas Kedokteran Universitas Sam Ratulangi \\ RSUP Prof. Dr. R. D. Kandou Manado \\ Email: flowsoverseas@gmail.com
}

\begin{abstract}
Stroke is a cardiovascular disease which is the second rank of worldwide disease leading to death. Hospitalization is a treatment process which including patient to stay at hospital and length of stay (LOS) is a calculated time periode when patient admitted until discharged. This studywas aimed to obtain the profile of hospitalized stroke patients' LOS at Prof. Dr. R. D. Kandou Hospital Manado from July 2015 to Juni 2016. This was a descriptive retrospective study using secondary data of the medical records. Samples consisted of 293 patients. The results presented ischemic stroke in $58.02 \%$ with LOS 6.84 days and hemorrhagic stroke in $41.98 \%$ with LOS 10.84 days. Patients with the highest LOS were females with hemorrhagic stroke (11.04 days); age 45-54 years (9.47 days); hemorrhagic stroke with hypertension (11.26 days); hemorrhagic stroke without dyslipidemia (10.67 days); hemorrhagic stroke with DM type 2 (12.67 days); and hemorrhagic stroke with tuberculosis (23.50 days). Conclusion: In this study, hemorrhagic stroke patients had higher LOS.
\end{abstract}

Keywords: stroke, length of stay.

\begin{abstract}
Abstrak: Stroke adalah penyakit kardiovaskular yang menempati peringkat kedua sebagai penyakit yang menyebabkan kematian di dunia. Pelayanan rawat inap merupakan proses perawatan pasien dengan menginap di rumah sakit dan length of stay (LOS) merupakan periode yang dihitung ketika pasien masuk hingga keluar dari rumah sakit. Penelitian ini bertujuan untuk mengetahui gambaran LOS pada pasien stroke rawat inap di RSUP Prof. Dr. R. D. Kandou Manado periode Juli 2015-Juni 2016. Jenis penelitian ialah deskriptif retrospektif dengan menggunakan data sekunder pasien stroke periode Juli 2015-Juni 2016 dari bagian rekam medik. Sampel penelitian berjumlah 293 pasien. Hasil penelitian menunjukkan persentase jumlah pasien stroke iskemik 58,02\% dengan LOS 6,84 hari dan persentase jumlah pasien stroke hemoragik 41,98\% dengan LOS 10,64 hari. Pasien stroke dengan LOS tertinggi terdapat pada jenis kelamin perempuan dengan stroke hemoragik, 11,04 hari; usia 45-54 tahun, 9,47 hari; stroke hemoragik dengan hipertensi, 11,26 hari; stroke hemoragik tanpa dislipidemia, 10,67 hari; stroke hemoragik dengan DM tipe 2, 12,67 hari; stroke dengan komplikasi, 9,33 hari; stroke hemoragik dengan pneumonia, 10,65 hari; dan stroke hemoragik dengan tuberculosis, 23,50 hari. Simpulan: Pasien stroke hemoragik memiliki LOS yang lebih tinggi.
\end{abstract}

Kata kunci: stroke, lama rawat

Stroke atau penyakit serebrovaskular adalah penyakit yang terjadi karena berhentinya aliran darah melalui sistem suplai arteri otak. ${ }^{1}$ Stroke adalah istilah 
yang meliputi terjadinya infark sistem saraf pusat, iskemia (dan atau silent CNS), perdarahan (ICH, silent cerebral hemorrage. subarachnoid hemorrhage) dan dapat disebabkan oleh thrombosis vena atau etiologi yang belum termasuk ke dalam klasifikasi. ${ }^{2}$ Faktor risiko penyebab stroke adalah tekanan darah tinggi, diabetes, atrial fibrilation, kadar kolesterol tinggi, merokok, alkohol dan penggunaan obat-obatan terlarang. ${ }^{1}$ Bahkan, studi terbaru menyebutkan polusi udara muncul sebagai faktor risiko stroke sedunia. ${ }^{3}$

Stroke menempati peringkat kedua sebagai penyakit yang paling sering menyebabkan kematian di dunia, yaitu 6,7 juta kematian setiap tahun. ${ }^{4}$ Jumlah penderita penyakit stroke di Indonesia pada tahun 2013 berdasarkan diagnosis tenaga kesehatan (Nakes) adalah 1.236.825 orang $(7,0 \%)$ dan berdasarkan diagnosis Nakes/gejala adalah kira-kira 2.137.941 orang $(12,0 \%)^{5}$

Rawat inap adalah pelayanan pasien untuk observasi, diagnosis, pengobatan, rehabilitasi medis dan atau upaya pelayanan kesehatan lainnya dengan menginap di rumah sakit. ${ }^{6}$

Length of Stay (LOS) merupakan gambaran lamanya seorang pasien berada di rumah sakit untuk menerima perawatan. LOS disebutkan sebagai indikator penting untuk menentukan keberhasilan terapi. Semakin sedikit waktu pasien berada di rumah sakit, semakin dapat dikatakan efektif dan efisien pelayanan di rumah sakit. ${ }^{8,9}$

Dengan meninjau hal-hal di atas, penelitian ini bertujuan untuk mengetahui gambaran length of stay pada pasien stroke rawat inap di RSUP Prof. Dr. R. D. Kandou Manado periode Juli 2015-Juni 2016.

\section{METODE PENELITIAN}

Jenis penelitian ini ialah deskriptif retrospektif dengan menggunakan data sekunder pasien stroke periode Juli 2015Juni 2016 di Bagian Rekam Medik RSUP Prof. Dr. R. D. Kandou Manado. Data yang diambil meliputi, usia, jenis kelamin, diagnosis stroke, diagnosis sekunder, komplikasi, dan data lama rawat pasien. Penelitian dilakukan pada bulan OktoberNovember 2016. Data hasil penelitian diolah berdasarkan variabel.

\section{HASIL PENELITIAN}

Penelitian yang dilakukan dengan mengumpulkan data sekunder dari rekam medik pasien stroke rawat inap dengan diagnosis stroke di RSUP Prof. Dr. R. D. Kandou Manado periode Juli 2015-Juni 2016 diperoleh 293 pasien yang memenuhi kriteria inklusi.

Pada Tabel 1 jumlah stroke iskemik sejumlah 170 orang $(58,02 \%)$ sedangkan stroke hemoragik sejumlah123 orang (41,98\%). Rata-rata LOS pasien stroke iskemik adalah 6,84 hari dan stroke iskemik 10,64 hari.

Tabel 1. Distribusi Kejadian Stroke Berdasarkan Jenis Stroke

\begin{tabular}{cccc}
\hline Jenis Stroke & N & $\%$ & $\begin{array}{c}\text { LOS } \\
\text { (hari) }\end{array}$ \\
\hline Stroke Iskemik & 170 & 58,02 & 6,84 \\
Stroke Hemoragik & 123 & 41,98 & 10,64 \\
Total & 293 & 100 & 8,43 \\
\hline
\end{tabular}

Tabel 2 menunjukkan dstribusi pasien stroke jenis kelamin laki-laki sejumlah 162 orang $(55,29 \%)$ dan pasien stroke jenis kelamin perempuan sejumlah 131 orang $(44,71 \%)$. Pasien laki-laki dengan stroke iskemik sejumlah 93 orang memiliki ratarata LOS 6,82 hari dan stroke hemoragik sejumlah 68 orang memiliki rata-rata LOS 10,20 hari. Pada pasien perempuan ditemukan stroke iskemik sejumlah 77 orang memiliki LOS 6,93 hari dan stroke hemoragik sejumlah 55 orang memiliki rata-rata LOS 11,04 hari.

Tabel 3 menggambarkan distribusi LOS pasien stroke berdasarkan usia ditemukan hasil: Pasien stroke berusia $<45$ tahun sejumlah 45 orang memiliki rata-rata LOS 8,42 hari (8-9 hari), pasien stroke berusia 45-54 tahun sejumlah 72 orang ditemukan rata-rata LOS 9,47 hari (9-10 hari), pasien stroke berusia 55-64 tahun 
sejumlah 95 orang memiliki rata-rata LOS 8,37 (8-9 hari), pasien stroke berusia 65-70 tahun sejumlah 37 orang memiliki rata-rata LOS 6,59 (6-7 hari) dan pasien stroke berusia $>70$ tahun sejumlah 44 orang memiliki rata-rata LOS 8,52 hari (8-9 hari). Berdasarkan data di atas, pasien stroke berusia 55-64 tahun $(32,43 \%)$ berjumlah paling banyak dan LOS yang paling tinggi pada pasien berusia 45-54 tahun yaitu 9,47 hari (9-10 hari.)

Tabel 4 memperlihatkan distribusi LOS pasien stroke berdasarkan faktor risiko hipertensi, didapatkan bahwa pasien stroke dengan faktor risiko hipertensi sejumlah 136 orang $(46,42 \%)$ dan pasien stroke tanpa faktor risiko hipertensi sejumlah 157 orang $(53,58 \%)$. Pasien stroke iskemik dengan faktor risiko hipertensi sejumlah 72 orang memiliki ratarata LOS 6,99 hari dan pasien stroke iskemik tanpa hipertensi sejumlah 98 orang dengan LOS 6,78 hari. Pada pasien stroke hemoragik dengan hipertensi sejumlah 64 orang memiliki rata-rata LOS 11,26 hari dan pasien stroke hemoragik tanpa hipertensi sejumlah 59 orang memiliki ratarata LOS 9,83 hari. Hasil ini menunjukkan, pasien stroke dengan faktor risiko hipertensi terbanyak adalah pasien stroke iskemik dan LOS paling tinggi ada pada pasien stroke hemoragik dengan faktor risiko hipertensi.

Tabel 5 memperlihatkan distribusi LOS pasien stroke berdasarkan faktor risiko dislipidemia, yaitu pasien stroke dengan faktor risiko dislipidemia sejumlah 44 orang $(15 \%)$ dan pasien stroke tanpa faktor risiko dislipidemia sejumlah 249 orang (85\%). Pasien stroke iskemik dengan faktor risiko dislipidemia sejumlah 25 orang memiliki rata-rata LOS 6,24 hari dan pasien stroke iskemik tanpa dislipidemia sejumlah 145 orang memiliki rata-rata LOS 6,98 hari. Pasien stroke hemoragik dengan faktor risiko dislipidemia sejumlah 18 orang memiliki rata-rata $\operatorname{LOS} 7,81$ hari dan pasien stroke hemoragik tanpa dislipidemia sejumlah 105 orang memiliki rata-rata LOS 10,67 hari. Jumlah pasien stroke dengan faktor risiko dislipidemia lebih sedikit daripada pasien stroke tanpa dislipidemia dan LOS tertinggi ada pada pasien stroke hemoragik tanpa dislipidemia.

Tabel 6 memperlihatkan distribusi LOS pasien stroke berdasarkan faktor risiko DM tipe 2, yaitu pasien stroke dengan faktor risiko DM tipe 2 sejumlah 34 orang $(11,60 \%)$ dan pasien stroke tanpa faktor risiko DM tipe 2 sejumlah 259 orang $(88,40 \%)$. Pasien stroke iskemik dengan faktor risiko DM tipe 2 sejumlah 25 orang memiliki rata-rata LOS 7,72 hari dan pasien stroke iskemik tanpa DM tipe 2 sejumlah 145 orang memiliki rata-rata LOS 6,72 hari. Pasien stroke hemoragik dengan faktor risiko dislipidemia sejumlah 9 orang memiliki rata-rata LOS 12,67 hari dan pasien stroke hemoragik tanpa DM tipe 2 sejumlah 114 orang memiliki rata-rata LOS 10,41 hari. Jumlah pasien stroke paling banyak adalah pasien stroke tanpa DM tipe 2 dan LOS paling tinggi ada pada pasien stroke hemoragik dengan DM tipe 2.

Tabel 7 menunjukkan distribusi LOS pasien stroke berdasarkan komplikasi, pasien stroke dengan adanya komplikasi sejumlah 52 orang $(17,40 \%)$ memiliki ratarata LOS 9,33 hari hari (9-10 hari) dan pasien stroke tanpa komplikasi sejumlah 241 orang $(82,6 \%)$ memiliki rata-rata LOS 8,23(8-9 hari). Jumlah pasien stroke dengan komplikasi lebih sedikit dan pasien stroke dengan komplikasi memiliki rata-rata LOS yang lebih tinggi.

Data penelitian pada Tabel 8 menyatakan distribusi LOS pasien stroke berdasarkan komplikasi stroke ditemukan hasil yaitu, pasien stroke iskemik dengan ulkus dekubitus sejumlah 3 orang memiliki rata-rata LOS 10,67 hari dan pasien stroke hemoragik dengan ulkus dekubitus sejumlah 1 orang memiliki rata-rata LOS 5,00 hari. Pasien stroke iskemik dengan pneumonia sejumlah 18 orang memiliki rata-rata LOS 8,44 hari dan pasien stroke hemoragik dengan pneumonia sejumlah 19 orang memiliki rata-rata LOS 10,65 hari. Pasien stroke iskemik dengan ISK sejumlah 6 orang memiliki rata-rata LOS 9,33 hari 
dan pasien stroke hemoragik dengan ISK sejumlah 6 orang memiliki rata-rata LOS 9,83 hari. Komplikasi paling banyak yang dialami pasien stroke iskemik dan hemoragik ialah pneumonia. LOS tertinggi terdapat pada pasien stroke iskemik dengan ulkus dekubitus.

Tabel 2. Distribusi LOS Pasien Stroke Berdasarkan Jenis Kelamin

\begin{tabular}{cccccccc}
\hline \multirow{2}{*}{$\begin{array}{c}\text { Jenis } \\
\text { Kelamin }\end{array}$} & $\mathbf{N}$ & $\boldsymbol{\%}$ & \multicolumn{2}{c}{ Stroke Iskemik } & & \multicolumn{2}{c}{ Stroke Hemoragik } \\
\cline { 4 - 5 } & & & $\mathbf{N}$ & LOS (hari) & & $\mathbf{N}$ & LOS (hari) \\
\hline Laki-laki & 162 & 55.29 & 93 & 6.82 & & 68 & 10.20 \\
Perempuan & 131 & 44.71 & 77 & 6.93 & & 55 & 11.04 \\
Total & 293 & 100 & 170 & 6.84 & & 123 & 10.64 \\
\hline
\end{tabular}

Tabel 3. Distribusi LOS Pasien Stroke Berdasarkan Usia

\begin{tabular}{cccc}
\hline $\begin{array}{c}\text { Usia } \\
\text { (tahun) }\end{array}$ & $\mathbf{N}$ & $\mathbf{\%}$ & $\begin{array}{c}\text { LOS } \\
\text { (hari) }\end{array}$ \\
\hline$<45$ tahun & 45 & 15,35 & 8,42 \\
45-54 tahun & 72 & 24,57 & 9,47 \\
55-64 tahun & 95 & 32,43 & 8,37 \\
65-70 tahun & 37 & 12,63 & 6,59 \\
$>70$ tahun & 44 & 15,02 & 8,52 \\
Total & 293 & 100 & 8,43 \\
\hline
\end{tabular}

Tabel 4. Distribusi LOS Pasien Stroke Berdasarkan Hipertensi

\begin{tabular}{ccccccc}
\hline Hipertensi & $\mathbf{N}$ & $\boldsymbol{\%}$ & \multicolumn{2}{c}{ Stroke Iskemik } & \multicolumn{2}{c}{ Stroke Hemoragik } \\
& & & $\mathbf{N}$ & LOS (hari) & $\mathbf{N}$ & LOS (hari) \\
\hline Ada & 136 & 46.42 & 72 & 6.99 & 64 & 11.26 \\
Tidak Ada & 157 & 53.58 & 98 & 6.78 & 59 & 9.83 \\
Total & 293 & 100 & & 6.84 & & 10.64 \\
\hline
\end{tabular}

Tabel 5. Distribusi LOS Pasien Stroke Berdasarkan Dislipidemia

\begin{tabular}{ccccccc} 
Dislipidemia & $\mathbf{N}$ & $\boldsymbol{\%}$ & \multicolumn{2}{c}{ Stroke Iskemik } & \multicolumn{2}{c}{ Stroke Hemoragik } \\
& & & $\mathbf{N}$ & LOS (hari) & $\mathbf{N}$ & LOS (hari) \\
Ada & 44 & 15,00 & 25 & 6.24 & 18 & 7.81 \\
Tidak Ada & 249 & 85,00 & 145 & 6.98 & 105 & 10.67 \\
Total & 293 & 100 & & 6.84 & & 10.64 \\
\hline
\end{tabular}

Tabel 6. Distribusi LOS Pasien Stroke Berdasarkan DM tipe 2

\begin{tabular}{ccccccc}
\hline DM tipe 2 & $\mathbf{N}$ & $\mathbf{\%}$ & \multicolumn{2}{c}{ Stroke Iskemik } & \multicolumn{2}{c}{ Stroke Hemoragik } \\
\cline { 4 - 7 } & & & $\mathbf{N}$ & LOS (hari) & $\mathbf{N}$ & LOS (hari) \\
\hline Ada & 34 & 11,60 & 25 & 7.72 & 9 & 12.67 \\
Tidak Ada & 259 & 88,40 & 145 & 6.72 & 114 & 10.41 \\
Total & 293 & 100 & & 6.84 & & 10.64 \\
\hline
\end{tabular}


Tabel 7. Distribusi LOS Berdasarkan Kejadian Komplikasi Stroke

\begin{tabular}{cccc}
\hline Komplikasi & N & \% & LOS (hari) \\
\hline Ada & 51 & 17,40 & 9,33 \\
Tidak Ada & 242 & $82 ., 6$ & 8,23 \\
Total & 293 & 100 & 8,43 \\
\hline
\end{tabular}

Tabel 8. Distribusi LOS Pasien Stroke Dengan Komplikasi

\begin{tabular}{cccccc}
\hline Komplikasi & $\mathbf{N}$ & \multicolumn{2}{c}{ Stroke Iskemik } & \multicolumn{2}{c}{ Stroke Hemoragik } \\
\cline { 3 - 6 } Stroke & & $\mathrm{N}$ & LOS (hari) & $\mathrm{N}$ & LOS (hari) \\
\hline Ulkus & 4 & 3 & 10.67 & 1 & 5.00 \\
dekubitus & & & & & \\
Pneumonia & 37 & 18 & 8.44 & 19 & 10.65 \\
ISK & 12 & 6 & 9.33 & 6 & 9.83 \\
Jumlah & 53 & & 6.84 & & 10.64 \\
\hline
\end{tabular}

\section{BAHASAN}

Jumlah pasien stroke yang dirawat inap di RSUP Prof. Dr. R. D. Kandou Manado periode Juli 2015-Juni 2016 dengan stroke iskemik terjadi lebih banyak, yaitu sebanyak 170 orang $(58,02 \%)$ sedangkan stroke hemoragik sebanyak 123 orang (41,98\%). Hal ini sesuai dengan penelitian yang dilakukan di RSUD Kabupaten Solok Selatan, stroke iskemik yang lebih tinggi jumlahnya yaitu $(61,46 \%)$ sedangkan stroke hemoragik $(38,54 \%){ }^{9}$ Penelitian CDC Korea juga menemukan jumlah stroke iskemik $71,8{ }^{10}$ Penelitian di Rumah Sakit PKU Muhammadiyah Yogyakarta diperoleh rata-rata lama rawat pasien stroke 9.37 hari (9-10 hari) dan stroke iskemik 8.10 hari (8-9 hari). ${ }^{11}$

Hasil penelitian distribusi LOS berdasarkan jenis kelamin, diperoleh jumlah pasien laki-laki lebih banyak dibandingkan pasien perempuan, dan LOS paling tinggi pada pasien perempuan dengan stroke hemoragik. Hal ini sesuai dengan penelitian yang dilakukan di RSUP Prof. Dr. R. D. Kandou Manado tahun 2012-2013 bahwa jumlah pasien laki-laki (52\%) lebih banyak dibanding perempuan. ${ }^{12}$ Meski penelitian di Singapura didapatkan hasil bahwa jenis kelamin tidak berkorelasi secara signifikan dengan $\operatorname{LOS}^{13}$ namun, hasil dari penelitian Sagrat Cor Hospital of Barcelona $^{14}$ menyatakan bahwa perempuan dan laki-laki memiliki perbedaan karakteristik faktor risiko, presentasi stroke, dan penyebab stroke yang dapat mempengaruhi LOS.

Hasil penelitian distribusi LOS pasien stroke berdasarkan usia pasien didapatkan pasien stroke berusia 55-64 tahun (32.43\%) berjumlah paling banyak dan LOS yang paling tinggi pada pasien stroke usia 45-54 tahun. Risiko seseorang mengalami stroke meningkat dua kali setiap dekade setelah usia 55 tahun, sehingga usia merupakan variabel penting dalam jumlah kejadian stroke. ${ }^{15,16}$

Hasil penelitian distribusi LOS pasien stroke berdasarkan faktor risiko hipertensi didapatkan pasien stroke dengan faktor risiko hipertensi terbanyak adalah pasien stroke iskemik dan LOS paling tinggi ada pada pasien stroke hemoragik dengan faktor risiko hipertensi. Suatu kondisi hipertensi sebagai faktor risiko stroke dikarenakan keadaan hipertrofi pembuluh darah dan remodeling yang kemudian mengakibatkan reduksi diameter pembuluh darah sehingga menyebabkan aterosklerosis. ${ }^{17}$

Hasil penelitian distribusi LOS pasien stroke berdasarkan faktor risiko dislipidemia, didapatkan jumlah pasien stroke dengan faktor risiko dislipidemia lebih sedikit daripada pasien stroke tanpa dislipidemia dan LOS tertinggi ada pada pasien stroke hemoragik tanpa 
dislipidemia. Kolesterol penting bagi membran sel, memori dan sebagai bagian dalam pembentukan asam empedu, vitamin D dan hormon steroid.. ${ }^{18}$

Hasil penelitian distribusi LOS pasien stroke berdasarkan faktor risiko DM tipe 2 didapatkan jumlah pasien stroke paling banyak adalah pasien stroke tanpa DM tipe 2 dan LOS paling tinggi ada pada pasien stroke hemoragik dengan DM tipe 2. Hasil yang ditemukan dalam penelitian yang dilakukan oleh CDC Korea yaitu pasien dengan diabetes memiliki peningkatan LOS yang signifikan pada pasien stroke dan infark serebri. ${ }^{10}$

Berdasarkan penelitian distribusi LOS pasien stroke berdasarkan komplikasi stroke, didapatkan jumlah pasien stroke dengan komplikasi berjumlah lebih sedikit dan pasien stroke dengan komplikasi memiliki rata-rata LOS yang lebih tinggi. Penelitian dari Danish National Indicator Project (DNIP) menemukan bahwa 25.2\% pasien stroke yang dirawat mendapat minimal 1 komplikasi medis selama dirawat. $^{20}$

Hasil penelitian terhadap komplikasi stroke diperoleh tiga komplikasi yang dialami pasien stroke. Komplikasi paling banyak yang dialami pasien stroke iskemik dan pasien stroke hemoragik ialah pneumonia. LOS tertinggi ada pada pasien stroke iskemik dengan ulkus dekubitus. Penelitian dari California Acute Stroke Prototype Registry menemukan pada pasien stroke dengan komplikasi pneumonia dan ISK mengalami LOS yang lebih tinggi sebesar $74 \%$ dan $46 \%$. Adanya komplikasi kandung kemih, termasuk ISK, inkontinensia atau retensi urun juga dapat menjadi sumber infeksi penyakit sehingga berpengaruh pada LOS pasien. ${ }^{21}$

\section{SIMPULAN}

Berdasarkan hasil penelitian dapat disimpulkan bahwa length of stay pasien stroke hemoragik lebih lama dibandingkan pasien stroke iskemik.

\section{DAFTAR PUSTAKA}

1. Price SA, Wilson LM. Patofisiologi. Konsep
Klinis Proses-proses Penyakit (6th ed). Jakarta: EGC, 2005.

2. AHA/ASA Expert Consensus Document. An Updated Definition of Stroke for the $21^{\text {st }}$ Century. Stroke Journal of American Heart Association. November 2013. [cited 2016 November] Available from: http://stroke.ahajournals.org/

3. The Lancet. The lancet neurology: For the first time, air pollution emerges as a leading risk factor for stroke worldwide; June 2016 [cited 2016 September]

4. World Health Organization. The top 10 causes death. 2014 [citied 2016 September]; Available from: http://www.who.int/mediacentre/factsh eets/fs310/en/

5. Pusat Data dan Informasi Kementerian Kesehatan RI. Info Datin. [majalah]; 2014

6. Sacco R, Kosner S, Broderick J, Caplan L, Cannor, Culebras A, et al. An updated definition of stroke for the $21^{\text {st }}$ century. American Heart Association/American Stroke Association; July 2013;44;2064-89.

7. Oxford University Press. Human and economic burden of stroke. Age and Ageing. 2009;38:4-5

8. Victorian Auditor-General's Repot. Hospital performance: length of stay. 2015$16: 22$

9. Dinata CA, Safrita Y, Sastri S. Gambaran Faktor Risiko dan Tipe Stroke pada Pasien Rawat Inap di Bagian Penyakit Dalam RSUD Kabupaten Solok Selatan Periode 1 Januari 2010 31 Juni 2012. [Artikel Penelitian]. Jurnal Kesehatan Andalas. Fakultas Kedokteran Universitas Andalas. 2013.

10. Kim SM, Hwang SW, Oh EH, Kang JK. Determinants of the length of stay in stroke patients. Osong Public Health Res Perspect. 2013;4(6):329-41.

11. Pradana A, Ardiansyah. Hubungan jenisjenis stroke dengan lama rawat inap di rumah Sakit. Yogyakarta: Fakultas Kedokteran Universitas Muhammadiyah Yogyakarta. Available from: digilib.fkik.umy.ac.id.

12. Patricia H, Kembuan MA, Tumboimbela MJ. Karakteristik penderita stroke iskemik yang di rawat inap di RSUP Prof. Dr. R. D. Kandou Manado. 
Journal e-clinic. Vol.3 No.1; 2015.

13. Tan WS, Heng BH, Chua K, Chan KF. Factors predicting inpatient rehabilitation length of stay of acute stroke patients in Singapore. Arch Phys Med Rehabil. 209;90(7):1202-7..

14. Arboix A, Massons J, Eroles LG, Targa C, Oliveres M, Comes Emili. Clinical predictors of prolonged hospital stay after acute stroke: relevance of medical complications. International Journal of Clinical Medicine, 2012, 3, 502-7 [citied 2016 September] Available from:

http://www.dx.doi.org/10.4236/ijcm.20 12.36090

15. Brown RD, Whisnant JP, Sicks RD, O'Fallon WM, Wiebers DO. Stroke incidence, prevalence, and survival: secular trends in Rochester, Minnesota, through 1989. Stroke. 1996;27:373380.

16. Wolf PA, D'Agostino RB, O'Neal MA, Sytkowski P, Kase CS, Belanger AJ, Kannel WB. Secular trends in stroke incidence and mortality: the Framingham Study. Stroke. 1992;23:1551-5.

17. Ladecola C, Philip BG. Hypertension, angiotensin, and sroke: beyond blood pressure. Stroke American Heart Association Journal. 2004;35:348-50.

18. Price Foundation Wise Traditions in Food, Farming and the Healing Arts. Weston A. 2007. [cited 2016 November]. Available from: www.westonaprice.org/know-yourfats/cholesterol-and-stroke

19. National Stroke Association. Understanding the connection between diabetes and the increased risk of stroke. [Brosur]. 2013.

20. Langhorne P, Robertson DJ, MacDonald $\mathrm{J}$, Jones C, McAlpine C, et al. American Heart Association. Medical Complication After Stroke. June 2000. [cited 2016 November 17]. Available from: stroke.ahajournals.org /content/31/6/1223. 